\title{
La mirada borrosa: poéticas del desenfoque y visiones oblicuas en la narrativa hispánica contemporánea*
}

\section{The Blurred Vision: Defocused Poetics and Oblique Views in the Contemporary Hispanic Narrative}

\begin{abstract}
Resumen
El sentido de la vista se ha implantado como el modelo cognitivo preferente en nuestra cultura; pero, ¿qué sucede cuando el orden visual se muestra falible?, ¿qué implicaciones y significados adquiere la presencia de un conjunto de enfermedades oculares que generan visiones defectuosas en la narrativa más reciente? En este trabajo se aborda, desde el paradigma de los estudios de género y de los estudios culturales, la obra de varias autoras latinoamericanas que han articulado en su narrativa diferentes desórdenes ópticos como la miopía, el estrabismo o la diplopía. Desde este planteamiento, se pretende demostrar que la presencia repetida de afecciones oculares ha configurado un motivo literario que se encuentra directamente relacionado con la emergencia de un nuevo posicionamiento estético. Las visiones deficientes se descubren, ahora, como la manifestación de ese mirar desde otro ángulo que precisaba el discurso femenino para oponerse a un régimen ocularcéntrico de raigambre masculina.
\end{abstract}

Palabras claves estética femenina, narrativa contemporánea, escritoras latinoamericanas, falogocularcentrismo, visión defectuosa.

* Este trabajo ha sido realizado gracias a la financiación del programa de contratos predoctorales FPU del Ministerio de Innovación, Cultura y Deporte (FPU17/00485) y forma parte de los resultados de investigación del GIR de Estética y Teoría de las Artes de la Universidad de Salamanca. 
CATEDRAL TomadA: Revista de crítica literaria latinoamericana / Journal of Latin American Literary Criticism

La mirada borrosa: poéticas del desenfoque y visiones oblicuas en la narrativa hispánica contemporánea

\begin{abstract}
The sense of sight has been established as the preferred cognitive model in our culture; however, ¿what happens when the visual order seems to be fallible?, ¿what implications and meanings acquires the presence of some eye diseases that generate defective views in the most recent narrative? This paper addresses, from the perspective of gender and cultural studies, the work of several Latin American female writers who have articulated in their narrative different optical disorders as myopia, strabismus or diplopia. From this approach, it is pretended to demonstrate that the repeated presence of eye diseases has configured a literary motive which is directly related to the emergence of a new aesthetic positioning. The deficient visions are discovered, nowadays, as the manifestation of a different look that was required from the female discourse to be against the ocularcentric and male regime.
\end{abstract}

Keywords Female aesthetics, contemporary narrative, Latin American female writers, ocularcentrism, blurred vision.

Mirada: visión estetizante Andrés Neuman, Barbarismos

Me he operado los ojos: la tecnología puntera LASIK ha quemado mi córnea hasta darle la forma de un ojo sano. Horas más tarde, mi cerebro reacciona: las imágenes que recibe, inusualmente nitidas, deben ser asumidas como reales. Y yo, de repente, veo como si nunca hubiera sido miope. Pero no os preocupéis: el espíritu de la cegatería no se quema con el láser.

Julia González Calderón, "12 momentos cuando te operas la miopía"

Las relaciones entre el arte y el sentido de la vista han generado, como es sabido, un debate en el que han participado diversas disciplinas. En este sentido, no es otra imagen que la de un ojo seccionado la que Buñuel elige para expresar una de las mayores revoluciones en la historia del arte: las vanguardias históricas; así, en la película Un perro andaluz (1929), la renovación estética viene determinada por un giro drástico en la forma de mirar que supondrá la apertura del arte hacia nuevos paradigmas. 
Ya desde la época clásica las implicaciones simbólicas de la visión y la ceguera se encuentran tematizadas. Así sucede en la tragedia griega Edipo rey, de Sófocles. En la conocida obra, la visión es entendida como un impedimento para acceder a la verdad; de este modo, mientras que Tiresias, el adivino ciego, es el único conocedor de las desgracias de Edipo, este vive ciego ante sus hechos. Por tanto, tras descubrir que ha asesinado a su padre y que se ha casado con su madre, Edipo no tiene otro remedio que arrancarse los ojos, emblema del mal que le ha conducido a la imposibilidad de conocer. A ello se suma la imagen del poeta ciego atribuida históricamente a Homero, una suposición que, si bien no está exenta de controversia, confirma la hipótesis de la ceguera como condición suprema del espíritu, pues parecería que solo un individuo ciego podría haber alcanzado la grandeza de la Ilíada y la Odisea.

En la historia de la literatura, son numerosas las obras que manejan el motivo de la ceguera. Entre ellas, cabe mencionar dos especialmente importantes en nuestra tradición: Ensayo sobre la ceguera (1995), del portugués José Saramago e Informe sobre ciegos — publicado inicialmente como parte de la novela Sobre héroes y tumbas (1961) - , del argentino Ernesto Sábato. Ambas obras plantean la idea de una ceguera física colectiva como modo de representar la ceguera ética y moral que llevará al ser humano a la ruina. Desde esta perspectiva, evidencian una preocupación por las formas de conocimiento de la cultura occidental que depositan toda su confianza en el sentido de la vista y que no han conducido sino al fracaso ético (Fonseca 95). La ceguera física se revela, entonces, como un castigo a la ceguera espiritual en que se ve sumida la humanidad tras la derrota de la vista como sistema único de percepción del mundo.

También en el ámbito de la pintura los vínculos entre la visión y el objeto artístico han suscitado abundantes reflexiones. Tal es el caso de los estudios que han querido explicar el estilo particular de algunos pintores a través de una relación directa con distintas enfermedades oculares o deficiencias visuales. En consecuencia, son numerosos los autores que han vinculado el impresionismo con la miopía en artistas como Renoir, Cezanne, Matisse o Lautrec; han estudiado la 
repercusión de las cataratas en la obra de Monet y de la degeneración macular en Degas; han afirmado que la pintura de Rembrandt es deudora de su ambliopía o han querido sostener que el estilo del Greco solo puede derivarse de su astigmatismo (Plata Rosas). A este respecto hace referencia una de las obras - El nervio óptico (2017) — que se trabajará en las siguientes páginas, donde la narradora arguye:

Cuando estudiaba historia del arte creía obedientemente que el Greco padecía un mal de ojos. Un astigmatismo agudo, que lo hacía ver como veía. Ahora sé que eso es un reduccionismo que no termina de explicar su cosmogonía, como la epilepsia no explica a Dostoievski ni la tuberculosis a Keats. (Gainza 147)

Sin embargo, si bien en la pintura se han analizado las afecciones oculares y sus consecuentes visiones trastornadas como motivos generadores de una estética determinada, hasta ahora la literatura se había detenido únicamente en la oposición directa entre la visión y la ceguera como maneras de percibir el mundo. Este hecho despertó el interés por analizar los motivos y significados de un nuevo posicionamiento estético observado en la última década de la narrativa en español escrita por mujeres; esto es, una apuesta literaria que sienta sus bases en los intersticios entre el ver y el no ver, en la visión entre o, lo que es lo mismo, la mirada defectuosa, borrosa o desenfocada a la que se destinan las siguientes páginas.

\section{El sentido de la vista y la construcción de una mirada femenina}

El crítico británico John Berger comienza su libro Modos de ver (1972) reparando en una cuestión que quizás de tan evidente se nos escapa: "la vista llega antes que las palabras". Por ello, parece indudable que la visión y, por ende, la escritura, están determinadas por nuestra forma de mirar; que nuestros modos de ver repercuten en las formas de interpretar la realidad. 
La primacía de la visión y del sentido de la vista como sistemas de conocimiento han fundado "en la civilización occidental un régimen socio-cultural que con toda propiedad puede denominarse ocularcentrismo" (Tapia Vásquez 25). El orden ocularcéntrico, instaurado en nuestra cultura desde la época clásica, ha depositado en el órgano de la vista, el ojo, todo su potencial cognoscitivo. Este régimen, que se sustenta en la supremacía del orden visual como dispositivo de aproximación al mundo, ha construido un paradigma epistemológico que equipara la visión y el conocimiento, disponiendo el sentido de la vista como sistema hegemónico de percepción. De tal modo, la vista, conocida como "el más noble de los sentidos", ha ejercido durante siglos su soberanía como modelo de comprensión de la realidad.

No obstante, si bien el ocularcentrismo nunca ha perdido su condición de régimen imperante, sí es cierto que en los últimos tiempos está experimentando un nuevo apogeo de sus dogmas ligado a lo que se ha denominado el "giro visual". Como señala Rodríguez de la Flor:

es un hecho difícilmente rebatible el del creciente peso y autoridad de una «cultura visual», que en su objeto y realizaciones y, también en lo que son sus propios métodos, parece inflexionar de modo tan potente al menos [...] como la antigua cultura [...] basada en el discurso, en el texto; en este sentido, el homo sapiens, erigido en la cultura logocéntrica, ha cedido el paso a un homo videns instruido y asentado en la cultura visual. (66)

Sin embargo, el régimen ocularcéntrico no ha estado exento de críticas; el ocularcentrismo ha sido discutido y cuestionado en la medida en que Occidente no solo ha primado la mirada como forma hegemónica de acceso al conocimiento, sino también al poder (Zafra 38). Así entendido, este modelo cognitivo podría encontrarse estrechamente vinculado con otro régimen dominante: el sistema patriarcal. Los principios ocularcéntricos se han desarrollado en paralelo al patriarcado y a los imperativos de la lógica masculina, por lo que diversos modos 
de resistencia a un conocimiento fundamentado en el privilegio de la vista se han generado desde los estudios de género.

Para hablar de la coyuntura de ambos regímenes socioculturales -el ocularcéntrico y el patriarcal-, Martin Jay propuso en 1993 el término falogocularcentrismo, con el que pretendía denunciar el sistema basado en la primacía de la visión como régimen eminentemente masculino. Si en los años 70 del siglo pasado, con el auge de la segunda ola del feminismo, se empiezan a vislumbrar las fallas del sistema patriarcal, este hecho coincide con el descubrimiento por parte de Luce Irigaray y de Hélène Cixous de la falibilidad del ocularcentrismo. Según la propia Irigaray (1974), este régimen, que había impulsado unas determinadas formas de ver heredadas del falogocentrismo, había sido empleado para excluir a las mujeres de los circuitos de conocimiento. De tal modo, si el orden ocularcéntrico había relegado el discurso femenino, se advertía su inoperancia como sistema epistemológico infalible y global.

Comenzaba a fraguarse, por tanto, un discurso que revelaba las grietas del orden visual con el fin de hallar aquellos resquicios por donde pudiera filtrarse la palabra femenina. Esta nueva perspectiva cuestionaba la capacidad del ojo como mecanismo válido y eficaz de conocimiento para la mujer, dado que el régimen ocularcéntrico la había alejado históricamente de las esferas del saber. Es ahí donde se sitúa la obra de Hélène Cixous, quien propone el modelo del no ver bien o del no ver viendo como el nuevo paradigma cognitivo de donde emanaría el discurso femenino. La mujer, que había sido excluida de los circuitos del conocimiento, debía buscar un sistema propio de percepción e interpretación de la realidad: el de la visión defectuosa. Si los discursos habían sido patrimonio exclusivamente masculino y los sujetos, cuando hablan, lo hacen siempre desde un lugar (Bruña 16), la mujer tenía que encontrar ese lugar desde donde enunciar y enunciarse; y este lugar, para Cixous, era el de la mirada miope. Se trata de una mirada situada entre la visión y la ceguera, una mirada condicionada por el velo invisible que limita y determina la visión femenina, opacada por el imperio de la mirada masculina. 
En el texto "Savoir" — recogido en la traducción española junto con "Un ver à soie" de Jacques Derrida bajo el título Velos (2001) — Hélène Cixous dice así:

Ella había nacido con el velo sobre los ojos. Una miopía muy poderosa tendía entre ella y el mundo sus magias enloquecedoras. Había nacido con el velo en el alma. Los anteojos son tenedores flojos apenas buenos para atrapar pequeños trozos de realidad. Como lo sabe el pueblo de los miopes, la miopía tiene su sede oscilante en el juicio. Hace reinar una eterna incertidumbre que ninguna prótesis disipa. En adelante ella no sabía. La Duda y ella siempre fueron inseparables. ¿Las cosas se habían ido o bien era ella quien las malveía? Jamás vio con seguridad. Ver era un creer cojeante. Todo era quizás. (23)

De este modo, se aprecia cómo su visión miope constituye una mirada propia con un enfoque distinto, alzada desde ese otro lugar que se enfrenta a la lógica masculina, y similar a aquella mirada estrábica que la escritora Maria-Mercè Marçal presentaría más tarde como característica de la mujer (1995). Si para Hélène Cixous "la miopía era su falta, su lazo, su velo natal imperceptible" (23), ella propone esta otra mirada como modelo cognoscitivo derivado de una visión de filiación femenina. Así, a través de la metáfora del velo y de la miopía, "Cixous cuestiona la existencia de una verdad, en la que se fundamenta el logos patriarcal: se puede ver [...] de otro modo" (Segarra 10).

Desde esta perspectiva, en el artículo "Me gustan tus ojos miopes (o del diálogo con Hélene Cixous para llevar al cuerpo, a la literatura, a la vida)", Vargas Quiroz advierte que "en la literatura, escribir puede ser asumido como una forma de mirar" (152) y que, pese a que la literatura es un viaje ciego, existe una "mirada que ve con los ojos cerrados y atentos, que mira no de frente como se ha enseñado a hacerlo, sino desde un lado, el propio, el lado de la subjetividad" (152). Por consiguiente, la autora apunta que el sujeto femenino tiene la tarea de mirar desde 
ese ver no viendo $\mathrm{y}$, desde ahí, ser capaz de deslegitimar discursos construidos históricamente. (150)

Estas posturas, por tanto, de la visión alterada o de la mirada borrosa, manifiestan la falibilidad del ocularcentrismo y del régimen visual dominante para albergar unas escrituras no-hegemónicas como son las de las mujeres. En este sentido, en contra de lo que sugiere el pensamiento androcéntrico, y como señala María Cunillera, "podemos obtener un modelo productivo a partir del punto ciego [...], desafiando al falocentrismo y la visualidad imperante" (76).

En "Mujeres y escritura(s)", Leonor Arfuch concluye que "la escritura femenina tendría que ver con la mirada crítica, autorreflexiva, que permita situarse en esa escena no ya para disputar la partida con el fiel acatamiento de sus reglas sino para jugar otro juego - un juego del revés — con otras cartas" (249). Este juego del revés equivaldría a esa mirada disímil de las visiones desenfocadas que proponen y materializan, desde el ámbito literario, las escritoras a las que se referirán las siguientes páginas. Desde este planteamiento, el recurso femenino de mirar de reojo o mirar por el rabillo de un solo ojo que sugería Sigrid Weigel en "La mirada bizca: sobre la historia de la escritura de las mujeres" ha encontrado su mayor proyección en la narrativa hispánica de los últimos años. Si Weigel defendía que "en vez de renunciar a la mirada, la mujer tendrá que agudizar su visión; no ponerse anteojos masculinos, sino desarrollar su propia mirada" (96), sta encomienda se ha cumplido en la más reciente narrativa latinoamericana mediante la asunción de la mirada borrosa como poética femenina de la diferencia; como reacción a un régimen masculino y ocularcentrista ligado a las nociones de eficiencia, eficacia e infalibilidad.

En definitiva, la literatura escrita por mujeres más contemporánea evidencia, desde el ámbito hispánico, un cierto modo de mirar que dista mucho de los modelos anteriores. Gran parte de estas propuestas se posiciona en los márgenes del inconsciente óptico, operando sobre las capacidades e incapacidades del orden visual para interpretar el mundo desde un ángulo femenino. Por tanto, el desafío que exponía María José Bruña de "hablar desde los márgenes, desde las fronteras 
o intersticios donde se sitúa la mujer para decir lo que no ha sido dicho, para decirse", de la necesidad de una "mirada estrábica, bizca, oblicua e irónica" (2122), irrumpe como la perspectiva asumida por la teoría y la práctica de la escritura de mujeres en América Latina. Se trataría, a fin de cuentas, de esa visión deficiente que ha sido empleada y proyectada como metáfora del discurso femenino y que se tratará de analizar a continuación.

\title{
Cortocircuitos de la mirada: hacia una estética de la visión defectuosa
}

\author{
Un miope solo sabe dudar \\ Cristina Rivera Garza, Viriditas \\ Aún con los ojos cerrados, era miope \\ Hélène Cixous, $\mathrm{Sa}[v]$ er
}

W. J. T. Mitchell señaló en Teoría de la imagen la dificultad de "mantener la visualidad fuera de la literatura, aunque el impulso de hacerlo se vea anunciado por el tópico del poeta ciego" (243). La idea de la ceguera como una condición privilegiada para el acceso al conocimiento y para el ejercicio de la escritura es la que se extrae de Jorge Luis Borges, una figura indispensable en todos los sentidos, pero más aún si hablamos de una tradición de la ceguera. Borges heredó de su familia paterna una afección ocular crónica y progresiva que lo dejó invidente en el año 1956; no obstante, en lugar de interpretar su enfermedad como un impedimento para la creación literaria, llegó a afirmar que la ceguera no solo no suponía una desdicha total, sino que podía considerarla como un don, como un modo de vida inclinado especialmente a la escritura (1980).

Sin embargo, se descubre en la literatura más contemporánea una propensión hacia los estadios intermedios entre el ver bien y el no ver, aquellos que, descreyendo de una visión firme y precisa para la condición femenina, rechazan también la ceguera como circunstancia preferente para la creación. En este contexto se ubican las propuestas de escritoras como la chilena Lina Meruane, las mexicanas 
Cristina Rivera Garza, Guadalupe Nettel y Verónica Gerber, la peruana Gabriela Wiener y la argentina María Gainza, quienes han articulado en su narrativa la inefectividad o inoperancia del sentido de la vista como sistema infalible para dar cuenta de la realidad, postura desde la que se desprende y por la que apuesta su literatura.

Se trata de un conjunto de autoras que ha recurrido a alteraciones o deficiencias del órgano de la vista para aludir a los lugares subordinados e insólitos desde donde perciben el mundo. No es de extrañar, por tanto, que la mexicana Daniela Tarazona (1975) se defina en su perfil de Twitter con solo tres palabras: "Escritora. Veo doble" (2010). Esta semblanza, en la medida en que relaciona su condición de escritora con su forma de ver, sugiere que su literatura deriva de esa percepción alterada de la realidad, de esa visión perturbada y antihegemónica. Así, se puede entender y validar esta nueva posición del ver-entre desde los parámetros que disponen tanto el no-ver — la ceguera — como el ver bien — la visión efectivacomo sistemas dependientes y subordinados a la hegemonía masculina del poder y la eficiencia.

$\mathrm{Si}$, tal y como se ha señalado, las nuevas poéticas se rebelan contra el tópico del poeta ciego, un ejemplo paradigmático de esta primera postura sería la novela Sangre en el ojo (2012). En ella, la narradora y ensayista Lina Meruane (Santiago de Chile, 1970) nos presenta a una mujer escritora que padece diabetes. El inexorable avance de su enfermedad desemboca en una retinopatía que le provocará derrames oculares y, en consecuencia, un emborronamiento progresivo de la visión. Este motivo conducirá a la protagonista y narradora a una pérdida gradual de la vista que terminará por dejarla completamente ciega y con una única posibilidad de volver a ver: el trasplante ocular.

Ante esta situación, Lucina se niega a escribir mientras sufra la ceguera, y no volverá a hacerlo hasta que recupere la vista tras el éxito del trasplante. En la novela, por tanto, la imposibilidad de ver conlleva la imposibilidad de escribir, puesto que la ceguera no supone ya una condición predilecta para el cultivo de la palabra, sino, más bien, un claro impedimento para interpretar la realidad en una 
sociedad que ha privilegiado el culto a la imagen y, por tanto, el sentido de la vista. Así entendido, y como advierte Nerea Oreja, "la literatura adquiere en Meruane un nuevo poder, una nueva misión, centrada en proponer nuevas formas de comprensión de la realidad" (81) que estarían relacionadas con la puesta en duda y el cuestionamiento de la falta de visión como mecanismo de escritura, pues, aunque prolijo, el motivo del poeta ciego no contempló nunca la literatura escrita por mujeres.

Pero, si se trata de considerar las implicaciones estéticas de la visión y la ceguera en el campo de la literatura, una de las primeras narradoras a las que se debe atender es, sin duda, Guadalupe Nettel (Ciudad de México, 1973). Autora de obras tan aclamadas como Después del invierno (2014), que ganó el Premio Herralde de Novela, la mexicana reconoce su propia deficiencia visual ${ }^{1}$ como una de las claves de su proyecto literario y afirma: "El tema de la ceguera siempre me ha obsesionado y he sacado provecho de ello en mis libros. Creo que determina bastante todo lo que escribo" (2014). Así, en su primera novela, El huésped (2006), narra la historia de una niña habitada por una presencia a la que llama La Cosa. Este ser amenaza con despojar a la protagonista de su identidad y la va sumiendo progresivamente en un espacio de tinieblas. De este modo, le arrebata el don de la vista y la enfrenta a la vida de las sombras, desde donde ella debe descifrar su propia forma de ver el mundo. Por consiguiente, "si bien la ceguera comienza como una amenaza, al final deja totalmente de serlo, pues es en realidad lo que permite a la protagonista adquirir una percepción ampliada [...], [una] nueva manera de ver, o más bien de no ver, la realidad exterior" (Ferrero Cándenas, Inés y Carlos Octavio Escobar Guzmán).

En una misma línea se presenta el cuento "Ptosis", recogido en el libro Pétalos y otras historias incómodas (2008). Partiendo de la anomalía que corresponde a una caída notable del párpado, referida en el título del relato, el texto

${ }^{1}$ La escritora padece una enfermedad ocular que, respondiendo a cuál es su problema en los ojos, define de la siguiente manera en una entrevista: "Hay una catarata, nistagmo, una mancha arriba de la córnea: un cóctel de enfermedades. Se dice que esa mancha es un síndrome de Peters y suele generar cataratas. Por eso muevo los ojos como si tuviera estrabismo" (Nettel 2014). 
cuenta la historia de un fotógrafo que se dedica a retratar a pacientes que van a someterse a una operación para mejorar el aspecto de sus ojos, con el objetivo de que haya constancia de los estados previo y posterior a la intervención estética. El personaje termina desarrollando una pasión desmedida por esa irregularidad física en la que distingue una belleza única, por lo que el cuento revela, nuevamente, ese lugar sobresaliente que posee la mirada en la obra de Guadalupe Nettel, "ese modo particular de mirar la realidad [...] que revela la sensibilidad artística de la autora y el modo de articular su lugar en el mundo" (Tapia Vázquez 8).

Sin embargo, es en la novela autobiográfica El cuerpo en que nací (2011) donde la enfermedad ocular adquiere una mayor significación. El texto, que sitúa la afección visual como motivo central en la vida de la narradora, arranca con la presentación de una protagonista que padece una patología ocular determinante en la medida en que condicionará un desarrollo personal definido por la anomalía:

Nací con un lunar blanco, o lo que otros llaman una mancha de nacimiento, sobre la córnea de mi ojo derecho. No habría tenido ninguna relevancia de no haber sido porque la mácula en cuestión estaba en pleno centro del iris, es decir justo sobre la pupila por la que debe entrar la luz hasta el fondo del cerebro. En esa época no se practicaban aún los trasplantes de córnea en niños recién nacidos: el lunar estaba condenado a permanecer ahí durante varios años. [...] El único consuelo que los médicos pudieron dar a mis padres en aquel momento fue la espera. [...] Mientras tanto, les aconsejaron someterme a una serie de ejercicios fastidiosos para que desarrollara, en la medida de lo posible, el ojo deficiente. Esto se hacía con movimientos oculares semejantes a los que propone Aldus Huxley en $E l$ arte de ver, pero también —y es lo que más recuerdo- por medio de un parche que me tapaba el ojo izquierdo durante la mitad del día. (11-12)

Desde este primer momento, la novela tratará de indagar en los diversos episodios de una existencia determinada por ese modo particular de enfrentarse a 
la vida que le imponen la enfermedad óptica y el uso del parche durante buena parte su infancia, una experiencia que, tal y como sucede de manera habitual, la convertía en el objeto de burla de sus compañeros. Pero la cuestión más interesante que se descubre en el texto es la idea de que la práctica de la escritura nace en Guadalupe Nettel de esa alteración visual que padece:

Un verano, finalmente el doctor Pentley anunció que podíamos dejar atrás el uso cotidiano del parche. Según él, mi nervio óptico se había desarrollado hasta el máximo de su capacidad. [...] Había empezado a leer un par de años atrás, pero, dado que ahora tenía un acceso continuo al universo nítido al que pertenecen las letras y los dibujos de los libros infantiles, decidí aprovecharlo. [...] El paso a la escritura se dio naturalmente. (17-19)

La enfermedad, en la medida en que ubica a la protagonista en una posición de marginalidad, la inclina hacia la literatura, que entiende como un espacio de refugio y autodeterminación. No obstante, el desorden visual no solo despierta en ella el interés por la escritura, sino que está relacionado directamente con el posicionamiento que toma su obra, pues su proyecto estético se asienta en los principios del temblor, del desequilibrio, de la inseguridad y de la duda; de ahí que afirme: "Después de todo, doctora Sazlavski, las dudas no me dan tanto miedo" (195).

Finalmente, la operación que durante largo tiempo había estado esperando y que le había supuesto tantos esfuerzos no podrá ejecutarse; cuando acude a la consulta del doctor, pese a que este la recibe con un informe positivo acerca del funcionamiento correcto de su nervio óptico, no todo son buenas noticias, pues, por el contrario, las esperanzas se frustran con respecto al cristalino: "La retina parecía totalmente pegada a éste, lo cual complicaba mucho la extracción de la catarata. [...] si cortábamos ahí, corríamos el riesgo de vaciar el ojo de su líquido" (193). Este hecho provoca que la visión alterada deje de entenderse como una 
circunstancia temporal para convertirse en una condición inherente a su persona, algo que constata una estética nacida de su mirada defectuosa: "Pensé mucho en la ceguera como posibilidad. [...] En esa semana y media tuvo lugar un cambio importante en mí, aunque no fuera perceptible de manera inmediata. Mis ojos y mi visión siguieron siendo los mismos pero ahora miraban diferente" (194). En definitiva, parece confirmarse que es desde esa mirada diferente desde donde se despliega una poética que apunta hacia la visión fracturada como un nuevo sistema de interpretación del mundo desde la óptica femenina.

A una nueva incursión en los terrenos de la miopía nos conduce la también mexicana Cristina Rivera Garza (1964), una escritora consagrada tanto en los circuitos de la narrativa como de la poesía y el ensayo, pero cuya obra digital no resulta tan conocida ${ }^{2}$. Sin embargo, esta parcela de su literatura merece una atención especial, puesto que en ella se albergan muchas de las claves interpretativas. Es en el marco de esta producción digital donde se sitúa el texto "La miopía es lo contrario de la fe" (2005), publicado en su blog No hay tal lugar. $U$ tópicos contemporáneos. En él, desarrolla una breve exégesis sobre la condición del miope incitada por la lectura del texto de Hélène Cixous: "Mientras la leo me doy cuenta que recuerdo ensayos memorables sobre la ceguera, pero que ' $\mathrm{Sa}(\mathrm{v}) \mathrm{er}$ ' es el primer texto que describe para mí, y casi a la perfección, este otro estado, el no-ver-bien, que acaso por menos dramático y más común es más transparente y menos comentado" (2005).

Rivera Garza es, por tanto, otra de las escritoras que reparan en esta circunstancia liminal entre el ver-bien y el no-ver que es la visión defectuosa. Como ya señalara Claudia Tapia, "la miopía representa una de las maneras en que el arte se relaciona con el mundo", generando un vínculo sugerente y enigmático (12). Desde este planteamiento, la escritora mexicana lanza una de las mejores

\footnotetext{
${ }^{2}$ Pese a que son mucho más numerosos los estudios que atienden a su obra impresa, sí se descubre algún trabajo referido a su obra digital, como los firmados por Vega Sánchez-Aparicio: "Respirar en el paisaje de los medios: las poéticas disruptivas de Cristina Rivera Garza" (2018) y "Escrituras mías de mí: la comunalidad en Cristina Rivera Garza” (2017).
} 
reflexiones en torno a los significados y la relevancia de esa mirada borrosa que genera la miopía:

Uno nace miope, se sabe. Pero si no fuera cuestión de genes dominantes, si no fuera una fatalidad, estoy segura de que la habría elegido. La miopía me obligó a vivir desde el inicio en un mundo difuso, sin límites fijos o claros, sin asideros. Ser miope era, sobre todo, dudar. Dudar de lo visto a medias por mí y dudar de lo visto claramente por otros. [...] ¿Cómo creer en ese mundo de bordes definidos y lindes exactos cuando nunca se le ha visto, cuando nunca se le ha experimentado? La miopía le pertenece a la región de los limbos, la produce, de hecho, y es, por ello, liminal. [...] La miopía es, luego entonces, crítica por naturaleza y, por ello, probablemente subversiva. El miope no cree, no puede; el miope descree categóricamente. [...] El miope toca y, tocando, ve un poco más. O ve de otra manera. [...] La miopía es lo contrario de la fe.

Esta afección ocular tan extendida entre la población occidental desencadena un modo distinto de ver, una forma otra de percibir el mundo modulada por el desenfoque. En este sentido, la ausencia de límites y contornos definidos suscita en Cristina Rivera Garza un rechazo hacia el universo de las certezas y las categorías fijas que se puede apreciar en el conjunto de su obra. La miopía supone, entonces, una forma de resistencia o de subversión de los modelos hegemónicos en la medida en que abre una posibilidad de mirar desde otro ángulo, de escapar de la visión imperante:

Recuerdo, con exactitud de no-miope, la primera vez que vi el mundo con ayuda de anteojos. [...] Después de un par de horas de éxtasis visual me quité los lentes y volví al mundo de las cosas informes [...]. Porque la miopía también es un refugio. [...] Cuando el mundo de coordenadas firmes y claras atosiga tanto, cuando los límites se anuncian con singular 
convicción y las ideas se enuncian con la autoridad repelente del dictador o del convencido, el miope puede borrarlo todo con sólo remover los anteojos.

Como muestra el fragmento anterior, el uso de anteojos supone primeramente un éxtasis visual inducido por esa mirada nítida y aguda que le confieren los lentes a la escritora. Sin embargo, la visión ortodoxa es para Cristina Rivera Garza una ilusión momentánea y pasajera que no va a mitigar de ningún modo su condición de miope, esa naturaleza o espíritu del no-ver-bien que determina tanto su vida como su escritura. La miopía se convierte, por tanto, en la brecha desde donde resistir a esa lógica masculina depositaria del poder y la palabra. En este sentido, la deficiencia visual no es para la autora sino la manera de relacionarse con esa mirada femenina que descree de los axiomas universales y que encuentra en las inseguridades e incertidumbres su potencia cognoscitiva.

Siguiendo esta misma línea de desconfianza en los sistemas ecuménicos y en las categorías absolutas concibe su obra la argentina María Gainza (Buenos Aires, 1975), una narradora emergente ${ }^{3}$ que despliega nuevas formas de articular las interacciones entre la mirada y el arte. En este sentido, en El nervio óptico (2017), donde solo el título ya da cuenta de los terrenos por los que se desplaza la novela, se manifiesta nuevamente la idea de la ausencia de una visión normativa como un campo abierto para la creación femenina. La novela, presentada como la narración en primera persona de una mujer cuya vida se ve amenazada por el cáncer, constituye casi una suerte de ensayo sobre la estética y la recepción del arte. Así, por medio de una composición que rehúye de ajustarse a taxonomías genéricas, el texto prorrumpe de las miradas heterodoxas y encuentra su espacio en los resquicios de aquella información que transmite, difuminada y a retazos, el nervio óptico.

${ }^{3}$ Si bien Gainza se estrenó como autora en 2011 con la compilación de ensayos sobre arte argentino Textos elegidos, no es hasta 2017 cuando publica su primera novela, El nervio óptico, a la que ha seguido recientemente La luz negra (2018). 
La autora va a manejar en este caso dos afecciones diferentes: la diplopía, un fenómeno que consiste en ver doble, y la mioquimia orbicular, una contracción involuntaria, rápida y repetida de la musculatura del ojo que se experimenta como una incómoda palpitación. De la visión duplicada que provoca la primera de ellas se vale Maria Gainza para aludir a una estética que mira tanto a la literatura como a la pintura, pues ambas disciplinas van de la mano en su obra. Sin embargo, se hace explícita en la narración la oposición desde uno de los mecanismos de ejercicio del poder, la industria médica, a esa visión doble que, por heterodoxa, debe ser subsanada:

Cuando era chica me llevaron al oculista porque veía doble. Diplopía se llamaba mi afección. Para corregirla me hacían mirar a través de un aparato donde dos siluetas del gato Silvestre flotaban separadas por un espacio en blanco. Yo debía unirlas con la fuerza de mis músculos oculares, acercarlas hasta hacerlas encajar una sobre otra. (Nervio 62)

La segunda afección supone una nueva alteración de la vista ocasionada, esta vez, por un cierre involuntario de los párpados que produce una visión intermitente: "vine al consultorio porque desde hace varios días me late el ojo derecho. Me palpita de una forma ridícula, intensa; el párpado inferior, sobre todo. A veces creo que me va a explotar" (89). El sistema nervioso recibe, entonces, una información interrumpida y discontinua que debe tratar de recomponer. Si bien el doctor le asegura que no debe preocuparse, ya que se trata únicamente de "una mioquimia, un temblor involuntario de las fibras musculares producto de una irritación" (95), se descubre, en ambos incidentes, ese rendimiento de las enfermedades oculares y sus consecuentes visiones alteradas como dispositivos catalizadores de la preocupación ética y estética de estas autoras ante los modelos hegemónicos del presente. Que la medicina sea la encargada de administrar los actos de visión disidentes está sugiriendo la preferencia social e institucional hacia las visiones normativas como mecanismos transmisores del engranaje político y 
cultural dominante. Por consiguiente, diplopía y mioquimia emergen en El nervio óptico como dos anomalías con una misma intención compartida: reflejar esta nueva toma de posición desde el campo literario frente a los sistemas imperantes. Si a ello sumamos, además, "la fractura que produce el embarazo y la maternidad en la mujer", otro argumento fundamental en la novela tal y como ha apuntado recientemente Ana Gallego (11), se constata un sustrato feminista que, aunque pudiera pasar desapercibido en favor de otras lecturas, se hace patente en el texto.

Optando, en esta ocasión, por el género ensayístico, la mexicana Verónica Gerber Bicecci (Ciudad de México, 1981) presenta el texto "Ambliopía”, primero de los recogidos en el libro Mudanza (2017). La escritora y artista visual, autora también de la novela Conjunto vacío (2015), se adivina como de una de las voces más sugerentes y seductoras en la narrativa hispánica de los últimos años. Este breve ensayo constituye, seguramente, uno de los ejemplos más evidentes de las vinculaciones entre la estética y las deficiencias ópticas. En el texto, la autora atiende a otra de las afecciones más comunes del ojo: la ambliopía ${ }^{4}$, también llamada, en términos coloquiales, la enfermedad del ojo vago o, como ella dice, "el síndrome del ojo flojo" (11), cuya patología explica del siguiente modo:

Mi ojo derecho seguía un camino errante e indescifrable, como si no fuera mío, como si no fuera yo quien lo controlaba. Más que una lente para corregir, necesitaba un ventilador que se llevara los cúmulos emborronados. Lo que veía era tan inestable, tan desigual, que terminó por asustarme. No tenía idea de que había un extraño alojado en mi córnea. Nací con un solo ojo y lo había ignorado por completo. (Mudanza 10)

Esta visión casi monocular provocada por la ambliopía permitirá a Verónica Gerber desplegar un nuevo alegato a favor de la visión defectuosa, a la vez que todo un manifiesto acerca de su propia estética. En esta dirección, la autora se pregunta:

\footnotetext{
${ }^{4}$ Es también un hecho destacable que Gerber haya optado por @ambliopia como su nombre de usuario en Twitter.
} 
"Cómo saber qué es ver bien si siempre has visto igual, si no hay referente alguno ni punto de comparación. [...] Descubrí que al tapar mi ojo izquierdo podía ver como a través de un caleidoscopio, pero obstruido y monocromático, defectuoso" (10). Por tanto, a pesar de los múltiples intentos del uso primeramente de un parche para forzar al ojo vago y, posteriormente, de lentes para evitar que el ojo sano se canse demasiado y deje de trabajar, su mirada sigue anclada en una visión voluble y deficiente.

Será, también, desde este panorama desde donde emerja su escritura. En este sentido, afirma que ha "buscado personajes con destinos ambliopes, aquellos que, en una demencia consciente, deciden renunciar, abandonarse a la contingencia para poner su vida, cuerpo y trabajo en el mismo espacio de indeterminación" (2017: 16) y, sobre todo, que "ya no basta con ver, la reina es solo un tamiz. El suceso estético está en otra parte" (16). Si bien la obra de Verónica Gerber parece emanar de esa visión alterada y defectuosa de la realidad, el verdadero suceso estético del que ella habla reside únicamente en la palabra, en la manera de contar. Así entendido, que la autora afirme que "hay una parte que se deforma sin quererlo y una parte que procuramos deformar cuando contamos algo" (18) no hace más que confirmar la hipótesis de partida: que la mirada borrosa e incompleta interviene o activa los procesos de creación y que la deformación de la realidad tiene que ver con esos modos alterados de percepción que actúan como agentes de subversión de las categorías establecidas.

Por último, no quisiera dejar de mencionar a Gabriela Wiener (Lima, 1975), reconocida periodista y escritora peruana afincada en España, quien publica en el número 127 de la revista Turia un texto que, si bien aborda diversas situaciones, afectos y emociones personales derivadas de la práctica del poliamor, presenta también algunos testimonios sumamente relevantes para las reflexiones planteadas en este trabajo. Así, hacia el final de la crónica que titula "Qué locura enamorarme yo de ti", Wiener cuenta cómo en un determinado momento se le rompen los lentes y cómo va posponiendo continuamente la visita a la óptica. Comprobará enseguida que ha postergado una y otra vez lo que casi se entiende como un deber inmediato 
solo porque encuentra un cierto placer en esa sensación de bruma que la invade cuando sus ojos se desprenden de la imposición social de los lentes para corregir las visiones desenfocadas. Ella, por el contrario, ha descubierto una parcela de satisfacción y de gozo en esa mirada borrosa y deficiente que le otorga modos renovados de ver y de entender su historia. Afirmará, por tanto, que "esa media voluntad de ceguera, ese no querer ver del todo [es] para la escritora como ponerse unos parches invisibles en los ojos. Al menos en uno" (223-224) y que "de alguna manera entiend[e] la escritura como ese movimiento de ponerse y sacarse un parche" (223).

\section{Conclusiones}

El ocularcentrismo, sistema basado en la primacía de la visión como modelo cognitivo, y el falogocentrismo, término propuesto por Jacques Derrida para aludir a la hegemonía masculina en las relaciones de poder y en los paradigmas epistemológicos, se pueden entender como dos regímenes cuyo desarrollo se ha producido en paralelo. No es de extrañar, por tanto, y como se ha señalado, que buena parte de la crítica hacia la preeminencia del sentido de la vista como mecanismo incuestionable de percepción se haya generado desde los estudios de género y, más concretamente, en el seno de la segunda ola feminista.

A este cuestionamiento se ha sumado también la literatura, que funge en los mejores casos como un discurso desestabilizador que trata de encontrar los espacios para representar aquellas grietas o fallas que otras disciplinas advierten solo de manera parcial. Tanto el no ver - la ceguera - como el ver bien — la visión eficiente - se descubren en la historia de la literatura como condiciones deudoras o estrechamente vinculadas con la lógica masculina. En este sentido, cobra especial relevancia la emergencia de un nuevo discurso que atiende a los estadios intermedios de la visión, es decir, una narrativa que ha encontrado en la mirada 
defectuosa un recurso innovador y sugerente para la búsqueda de una estética propiamente femenina.

En este contexto irrumpe un grupo de escritoras que explora esas visiones deficientes y trastocadas como metáforas de un nuevo posicionamiento estético que se aleja de los modelos precedentes. Este trabajo ha tratado de analizar y esclarecer las propuestas de las escritoras Lina Meruane, Guadalupe Nettel, Cristina Rivera Garza, María Gainza, Verónica Gerber y Gabriela Wiener en torno a la representación de las afecciones oculares y sus consecuentes miradas borrosas y desenfocadas con el fin de exponer los significados y la trascendencia de un modelo crítico que, desde la literatura, ha percibido en el ocularcentrismo - con sus dogmas de eficiencia e infalibilidad - la manifestación y proyección de un sistema patriarcal dominante que ha oprimido durante siglos el discurso femenino.

En consecuencia, si ya Hélène Cixous señalaba la necesidad que tenían las mujeres de ver de otro modo, alejándose así de la mirada universal y axiomática que había instaurado el patriarcado, la articulación de la visión-entre que realizan las autoras más contemporáneas evidencia la preocupación por participar y conquistar las esferas del saber mediante una visión miope, estrábica o ambliope que les permita adquirir esa mirada propia que durante tanto tiempo han perseguido. Las escritoras se han quitado definitivamente el velo masculino de los ojos y miran ahora desde su propia bruma, enfocando y desenfocando a su antojo y, lo que es más importante, sabiendo que solo desde un emborronamiento personal podrán lanzar su mirada al mundo. Por ello, estas poéticas del desenfoque son también, en su naturaleza feminista, poéticas de la resistencia estética y política. 


\section{Bibliografía}

Arfuch, Leonor. "Mujeres y escritura(s)" en Sociedad, n 22, 2003, pp. 235-249.

Berger, John. Modos de ver. Barcelona: Editorial Gustavo Gili, 2016 [1972].

Borges, Jorge Luis. "La ceguera", en Siete noches. México D. F.: Editorial Meló, 1980.

Bruña Bragado, María José. "La mirada bizca o breve historia de los feminismos: del sufragismo a la crisis de la masculinidad" en Verbeia, $\mathrm{n}^{\circ} 2,2018$, pp. $15-37$.

Cixous, Hélène. "Savoir” en Velos. Ed. y trad. Mara Negrón. México D.F.: Siglo XXI Editores, 2001.

Cunillera Pérez, María. "Metáforas de la voracidad del arte del siglo XX". Tesis. Universidad Complutense de Madrid, 2010.

Ferrero Cándenas, Inés y Carlos Octavio Escobar Guzmán. “El ojo cámara: mirada, belleza y corporalidad en la narrativa de Guadalupe Nettel” en Actas I Jornadas Internacionales Cuerpo y violencia en la Literatura y las Artes Visuales Contemporáneas. Buenos Aires: Universidad de Buenos Aires, 2017. Ponencia.

Fonseca, Marco Antonio. "La ceguera como motivo en Ensayo sobre la ceguera de José Saramago e Informe sobre ciegos de Ernesto Sábato". Tesis. Universidad Autónoma de Barcelona, 2008.

Gainza, María. El nervio óptico. Barcelona: Anagrama, 2017.

Gallego Cuiñas, Ana. "Últimas novelas del Río de la Plata en España: Fernanda Trías, Ariana Harwicz y María Gainza” en Cuadernos LIRICO, $\mathrm{n}^{\circ} 20$, 2019, pp. 1-18.

Gerber, Verónica. Mudanza. México D.F.: Almadía, 2017.

Irigaray, Luce. Espéculo de la otra mujer. Madrid: Akal, 2007 [1974].

Jay, Martin. "Falogocularcentrismo: Derrida e Irigaray”, en Ojos abatidos. La denigración de la visión en el pensamiento francés del siglo XX. Madrid, Ediciones Akal, 2008 [1993]. 
CATEDRAL Tomada: Revista literaria latinoamericana / Journal of Latin American Literary Criticism Marta Pascua Canelo

Marçal, Maria-Mercè. La pasión según Renée Vivien. Barcelona: Seix Barral, 1995, pp. 115-117.

Meruane, Lina. Sangre en el ojo. Barcelona: Caballo de Troya, 2012.

Mitchell, W. J. T. Teoría de la imagen: ensayos sobre representación verbal y visual. Madrid: Ediciones Akal, 2009, pp. 79-99.

Nettel, Guadalupe. El huésped. Barcelona: Anagrama, 2006.

Nettel, Guadalupe. "Ptosis" en Pétalos y otras historias incómodas. Barcelona: Anagrama, 2008.

Nettel, Guadalupe. El cuerpo en que nací. Barcelona: Anagrama, 2011.

Nettel, Guadalupe. "La ceguera determina mucho de lo que escribo". Entr. Cris Vilchez. Correo, 22 oct. 2014. Web. < https://diariocorreo.pe/peru/guadalupe-nettel-la-ceguera-determinamuch-22853/ > 17-12-2018.

Oreja Garralda, Nerea. "Sangre en el ojo: reflexiones en torno a la enfermedad, la (post)memoria y la escritura" en Perifrasis. Rev. Lit. Teor. Crit. vol. 9, $\mathrm{n}^{\mathrm{o}}$ 18, 2018, pp. 80-97.

Plata Rosas, Luis Javier. "Pintar con malos ojos: una mirada oftalmológica al arte". Nexos. Web. 1 sept. 2017. < https://www.nexos.com.mx/?p=33537 $>10-12-2018$.

Rivera Garza, Cristina. "La miopía es lo contrario de la fe". No hay tal lugar. Utópicos contemporáneos. Web. 11 ene. 2005. < http://cristinariveragarza.blogspot.com.es/2005/01/ > 27-11-2018.

Rodríguez de la Flor, Fernando. Giro visual. Primacía de la imagen y declive de la lecto-escritura en la cultura postmoderna. Salamanca: Delirio, 2009. Sánchez-Aparicio, Vega. "Escrituras mías de mí: la comunalidad en Cristina Rivera Garza" en Territorios del presente. Tecnología, globalización y mímesis en la narrativa en español del siglo XXI, Montoya, Jesús y Natalia Moraes Mena (eds.). Bern: Peter Lang, 2017, 135-149. 
Sánchez-Aparicio, Vega. "Respirar en el paisaje de los medios: las poéticas disruptivas de Cristina Rivera Garza” en Revista Landa, Vol. 7, nº 1, 2018, pp. 212-231.

Segarra, Marta. "Hélène Cixous: visión y creación" en Ver con Hélène Cixous, Marta Segarra ed. Barcelona: Icaria, 2006, pp. 7-12.

Tapia, Claudia. "El punctum caecum de la crítica literaria: la enfermedad del ojo en los detectives de Roberto Bolaño y Ricardo Piglia”. Tesis. Universidad de Concepción, 2014.

Tapia, Claudia. "La mirada miope de Roberto Bolaño: escritura de lo in/visible y lo in/significante" en Acta Literaria, ${ }^{\circ}$ 50, 2015, pp. 11-31.

Tapia Vázquez, Jamín G. "El imperio de la mirada: "Ptosis" de Guadalupe Nettel" en LEJANA. Revista Crítica de Narrativa Breve, n 9, 2016, pp. 1-13.

Tarazona, Daniela (@dtarazonav). Escritora. Veo doble. Sept. 2010. Twitter. < https://twitter.com/dtarazonav?lang=es $>10-12-2018$.

Vargas Quiroz, Andrea Paola. "Me gustan tus ojos miopes (o del diálogo con Hélene Cixous para llevar al cuerpo, a la literatura, a la vida" en $L a$ palabra, no 25, 2014, pp. 143-156.

Weigel, Sigrid. "La mirada bizca: sobre la historia de la escritura de las mujeres" en Estética feminista, Gisela Ecker ed. Barcelona: Icaria, 1986, pp. 6998.

Wiener, Gabriela. "Qué locura enamorarme yo de ti”. Turia, n 127, 2018, pp. 216-225.

Zafra, Remedios. Ojos y capital. Bilbao: Consonni, 2015. 